\title{
2019 Canadian guideline for physical activity throughout pregnancy
}

\author{
Michelle F Mottola, ${ }^{1}$ Margie H Davenport, ${ }^{2}$ Stephanie-May Ruchat, ${ }^{3}$ \\ Gregory A Davies, ${ }^{4}$ Veronica J Poitras, ${ }^{5}$ Casey E Gray, ${ }^{6}$ Alejandra Jaramillo Garcia, ${ }^{5}$ \\ Nick Barrowman, ${ }^{7}$ Kristi B Adamo, ${ }^{8}$ Mary Duggan, ${ }^{9}$ Ruben Barakat, ${ }^{10}$ Phil Chilibeck, ${ }^{11}$ \\ Karen Fleming, ${ }^{12}$ Milena Forte, ${ }^{13}$ Jillian Korolnek, ${ }^{14}$ Taniya Nagpal, $^{1}$ Linda G Slater, ${ }^{15}$ \\ Deanna Stirling, ${ }^{16}$ Lori Zehr $^{17}$
}

For numbered affiliations see end of article.

\section{Correspondence to Dr Margie H Davenport, Program for Pregnancy and Postpartum Health, Faculty of Kinesiology, Sport and Recreation, University of Alberta, Edmonton, Alberta T6G 2E1, Canada; \\ mdavenpo@ualberta.ca}

MFM, MHD and S-MR are joint first authors.

This article is being copublished in the Journal of Obstetrics and Gynaecology Canada. English version: 2018;40(11): 1549-1559. doi: 10.1016/ j.jogc.2018.07.001; French version: 2018;40(11):

1560-1570. 10.1016/ j.jogc.2018.09.003

Accepted 15 September 2018

Check for updates

(C) Author(s) (or their employer(s)) 2018. No commercial re-use. See rights and permissions. Published by BMJ.

To cite: Mottola MF

Davenport MH, Ruchat S-M

et al. Br I Sports Med

2018:52:1339-1346.

This joint SOCG/CSEP Clinical Practice Guideline has been prepared by the Guidelines Consensus Panel, reviewed by the Society of Obstetricians and Gynaecologists of Canada's (SOGC) Maternal Fetal Medicine and Guideline Management and Oversight Committees, and approved by the Board of the SOGC and the Board of Directors of the Canadian Society for Exercise Physiology (CSEP). This article is being copublished in the Journal of Obstetrics and Gynaecology Canada: English version 2018;40(11):1549-1559, https:// doi.org/10.1016/j.jogc.2018.07.001; French version: 2018;40(11):1560-1570. https://doi.org/10.1016/j. jogc.2018.09.003.

\section{ABSTRACT}

The objective is to provide guidance for pregnant women and obstetric care and exercise professionals on prenatal physical activity. The outcomes evaluated were maternal, fetal or neonatal morbidity, or fetal mortality during and following pregnancy. Literature was retrieved through searches of MEDLINE, EMBASE, PsycINFO, Cochrane Database of Systematic Reviews, Cochrane Central Register of Controlled Trials, Scopus and Web of Science Core Collection, CINAHL Plus with Full Text, Child Development \& Adolescent Studies, Education Resources Information Center, SPORTDiscus, ClinicalTrials.gov and the Trip Database from inception up to 6 January 2017. Primary studies of any design were eligible, except case studies. Results were limited to English-language, Spanish-language or Frenchlanguage materials. Articles related to maternal physical activity during pregnancy reporting on maternal, fetal or neonatal morbidity, or fetal mortality were eligible for inclusion. The quality of evidence was rated using the Grading of Recommendations Assessment, Development and Evaluation methodology. The Guidelines Consensus Panel solicited feedback from end users (obstetric care providers, exercise professionals, researchers, policy organisations, and pregnant and postpartum women). The development of these guidelines followed the Appraisal of Guidelines for Research and Evaluation II instrument. The benefits of prenatal physical activity are moderate and no harms were identified; therefore, the difference between desirable and undesirable consequences (net benefit) is expected to be moderate. The majority of stakeholders and end users indicated that following these recommendations would be feasible, acceptable and equitable. Following these recommendations is likely to require minimal resources from both individual and health systems perspectives.

\section{PREAMBLE}

These Guidelines provide evidence-based recommendations regarding physical activity throughout pregnancy in the promotion of maternal, fetal and neonatal health. In the absence of contraindications (see below for a detailed list), following these Guidelines is associated with (1) fewer newborn complications (ie, large for gestational age) and (2) maternal health benefits (ie, decreased risk of pre-eclampsia, gestational hypertension, gestational diabetes, caesarean section, instrumental delivery, urinary incontinence, excessive gestational weight gain and depression; improved blood glucose; decreased total gestational weight gain; and decreased severity of depressive symptoms and lumbopelvic pain). Physical activity is not associated with miscarriage, stillbirth, neonatal death, preterm birth, preterm/prelabour rupture of membranes, neonatal hypoglycaemia, low birth weight, birth defects, induction of labour or birth complications. In general, more physical activity (frequency, duration and/or volume) is associated with greater benefits. However, evidence was not identified regarding the safety or additional benefit of exercising at levels significantly above the recommendations. Prenatal physical activity should be considered a front-line therapy for reducing the risk of pregnancy complications and enhancing maternal physical and mental health. For pregnant women not currently meeting these Guidelines, a progressive adjustment towards them is recommended. Previously active women may continue physical activity throughout pregnancy. Women may need to modify physical activity as pregnancy progresses. There may be periods when following the guidelines is not possible due to fatigue and/or discomforts of pregnancy; women are encouraged to do what they can and to return to following the recommendations when they are able. These Guidelines were informed by an extensive systematic review of the literature, 
expert opinion, and end user consultation and considerations of feasibility, acceptability, costs and equity.

\section{RECOMMENDATIONS}

The specific recommendations in the 2019 Canadian Guideline for Physical Activity throughout Pregnancy are provided below with corresponding statements indicating the quality of the evidence informing the recommendations and the strength of the recommendations (explanations follow).

1. All women without contraindication should be physically active throughout pregnancy. Strong recommendation, moderate-quality evidence.

Specific subgroups were examined:

- Women who were previously inactive. Strong recommendation, moderate-quality evidence.

- Women diagnosed with gestational diabetes mellitus. Weak recommendation ${ }^{\mathrm{i}}$, low-quality evidence.

- Women categorised as overweight or obese (prepregnancy body mass index $\geq 25 \mathrm{~kg} / \mathrm{m}^{2}$ ). Strong recommendation ${ }^{\mathrm{ii}}$, low-quality evidence.

2. Pregnant women should accumulate at least $150 \mathrm{~min}$ of moderate-intensity ${ }^{\text {iii }}$ physical activity each week to achieve clinically meaningful health benefits and reductions in pregnancy complications. Strong recommendation, moderate-quality evidence.

3. Physical activity should be accumulated over a minimum of 3 days per week; however, being active every day is encouraged. Strong recommendation, moderate-quality evidence.

4. Pregnant women should incorporate a variety of aerobic and resistance training activities to achieve greater benefits. Adding yoga and/or gentle stretching may also be beneficial. Strong recommendation, high-quality evidence.

5. Pelvic floor muscle training (PFMT) (eg, Kegel exercises) may be performed on a daily basis to reduce the risk of urinary incontinence. Instruction on the proper technique is recommended to obtain optimal benefits. Weak recommendation ${ }^{\text {iv }}$, low-quality evidence.

6. Pregnant women who experience light-headedness, nausea or feel unwell when they exercise flat on their back should modify their exercise position to avoid the supine position. Weak recommendation ${ }^{\mathrm{v}}$, very-low quality evidence.

\footnotetext{
${ }^{\mathrm{i}}$ This was a weak recommendation because the quality of evidence was low, and the net benefit between women who were physically active and those who were not was small.

ii This was a strong recommendation because, despite low-quality evidence supporting physical activity during pregnancy for women categorised as overweight or obese, there was evidence from randomised controlled trials demonstrating an improvement in gestational weight gain and blood glucose.

iii Moderate-intensity physical activity is intense enough to noticeably increase heart rate; a person can talk but not sing during activities of this intensity. Examples of moderate-intensity physical activity include brisk walking, water aerobics, stationary cycling (moderate effort), resistance training, carrying moderate loads and household chores (eg, gardening, washing windows)

iv This was a weak recommendation because urinary incontinence was not rated as a 'critical' outcome and the evidence was of low quality.

${ }^{v}$ This was a weak recommendation because (1) the quality of evidence was very low, and (2) although harms were investigated there was limited available information to inform the balance of benefits and harms. This recommendation was primarily based on expert opinion.
}

\section{CONTRAINDICATIONS}

All pregnant women can participate in physical activity throughout pregnancy with the exception of those who have contraindications (listed below). Women with absolute contraindications may continue their usual activities of daily living but should not participate in more strenuous activities. Women with relative contraindications should discuss the advantages and disadvantages of moderate-to-vigorous intensity physical activity with their obstetric care provider prior to participation.

The following are absolute contraindications to exercise:

- Ruptured membranes.

- Premature labour.

- Unexplained persistent vaginal bleeding.

- Placenta praevia after 28 weeks' gestation.

- Pre-eclampsia.

- Incompetent cervix.

- Intrauterine growth restriction.

- High-order multiple pregnancy (eg, triplets).

- Uncontrolled type I diabetes.

- Uncontrolled hypertension.

- Uncontrolled thyroid disease.

- Other serious cardiovascular, respiratory or systemic disorder.

The following are relative contraindications to exercise:

- Recurrent pregnancy loss.

- Gestational hypertension.

- A history of spontaneous preterm birth.

- Mild/moderate cardiovascular or respiratory disease.

- Symptomatic anaemia.

- Malnutrition.

- Eating disorder.

- Twin pregnancy after the 28th week.

- Other significant medical conditions.

\section{STRENGTH OF THE RECOMMENDATIONS}

The Grading of Recommendations Assessment, Development and Evaluation (GRADE) system was used to grade the strength of the recommendations. Recommendations are rated as strong or weak based on the (1) balance between benefits and harms, (2) overall quality of the evidence, (3) importance of outcomes (ie, values and preferences of pregnant women), (4) use of resources (ie, cost), (5) impact on health equity, (6) feasibility and (7) acceptability.

\section{Strong recommendation}

Most or all pregnant women will be best served by the recommended course of action.

\section{Weak recommendation}

Not all pregnant women will be best served by the recommended course of action; there is a need to consider other factors such as the individual's circumstances, preferences, values, resources available or setting. Consultation with an obstetric care provider may assist in decision-making.

\section{QUALITY OF THE EVIDENCE}

The quality of the evidence refers to the level of confidence in the evidence and ranges from very low to high.

\section{High quality}

The Guidelines Consensus Panel is very confident that the estimated effect of physical activity on the health outcome is close to the true effect. 


\section{Moderate quality}

The Guidelines Consensus Panel is moderately confident in the estimated effect of physical activity on the health outcome; the estimate of the effect is likely to be close to the true effect, but there is a possibility that it is substantially different.

\section{Low quality}

The Guidelines Consensus Panel's confidence in the estimated effect of physical activity on the health outcome is limited; the estimate of the effect may be substantially different from the true effect.

\section{Very low quality}

The Guidelines Consensus Panel has very little confidence in the estimated effect of physical activity on the health outcome; the estimate of the effect is likely to be substantially different from the true effect.

\section{INTRODUCTION}

Regular physical activity across the lifespan is associated with substantial health benefits, including improvements in physical fitness and mental health, as well as decreased risk of chronic disease and mortality. ${ }^{1}$ Pregnancy is a unique period of a woman's life, where lifestyle behaviours, including physical activity, can significantly affect her health, as well as that of her fetus. ${ }^{2-13}$ Although guidelines around the world recommend women without contraindication engage in prenatal physical activity, ${ }^{14}$ fewer than $15 \%$ of women will actually achieve the minimum recommendation of $150 \mathrm{~min}$ per week of moderate-intensity physical activity during their pregnancy. ${ }^{15}$ Unfortunately, uncertainty among some pregnant women and obstetric care providers as to whether prenatal physical activity may increase the risk of miscarriage, growth restriction, preterm birth, fatigue or harm to the fetus have served as barriers to being active. ${ }^{16}$ Concerns over harms have not been substantiated by research and the risks of not engaging in prenatal physical activity have not been adequately emphasised. Over the last three decades, the rates of pregnancy complications such as gestational diabetes mellitus, pre-eclampsia, gestational hypertension and newborn macrosomia have risen dramatically, most likely as a consequence of rising rates of maternal obesity. ${ }^{17}{ }^{18}$ Physical activity has been proposed as a preventative or therapeutic measure to reduce pregnancy complications and optimise maternal-fetal health. ${ }^{19} 20$

These evidence-based guidelines apply to pregnant women, and target users including obstetric care providers, policymakers and fitness professionals who provide guidance on the impact of prenatal physical activity on maternal, fetal and neonatal health outcomes.

\section{METHODS}

The 2019 Canadian Guideline for Physical Activity throughout Pregnancy were developed according to the methodological strategy outlined in the Appraisal of Guidelines for Research and Evaluation (AGREE) II instrument. ${ }^{21}$ The goal of these guidelines was to provide evidence-based recommendations regarding physical activity during pregnancy in the promotion of maternal, fetal and neonatal health. The Guidelines Consensus Panel consisted of researchers in the field of prenatal exercise; methodological experts (AGREE II and GRADE; statistician and librarian); exercise professionals and representatives from the Canadian Society for Exercise Physiology (CSEP), the Society of Obstetricians and Gynaecologists of Canada (SOGC), the College of Family Physicians of Canada, the Canadian Association of Midwives, the Canadian
Table 1 'Critical' and 'important' outcomes selected by the Guidelines Consensus Panel

\begin{tabular}{|c|c|c|}
\hline \multicolumn{2}{|c|}{ 'Critical' outcomes } & 'Important' outcomes \\
\hline D & Miscarriage. & - Antepartum haemorrhage. \\
\hline 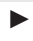 & Stillbirth. & - Inadequate gestational weight gain. \\
\hline 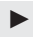 & Neonatal death. & - Total gestational weight gain. \\
\hline 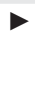 & Preterm birth. & $\begin{array}{l}\text { Delivery complications (instrumental } \\
\text { delivery, length of labour, vaginal } \\
\text { tears). }\end{array}$ \\
\hline$>$ & Gestational diabetes mellitus. & Birth defects. \\
\hline$>$ & Pre-eclampsia. & Lower back pain. \\
\hline$>$ & Gestational hypertension. & - Pelvic girdle pain. \\
\hline$>$ & Caesarean section. & $\begin{array}{l}\text { Urinary incontinence (during and } \\
\text { following pregnancy). }\end{array}$ \\
\hline$>$ & $\begin{array}{l}\text { Maternal mental health } \\
\text { (depression and anxiety during and } \\
\text { following pregnancy). }\end{array}$ & - Induction of labour. \\
\hline 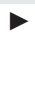 & Excessive gestational weight gain. & $\begin{array}{l}\text { Long-term maternal outcomes } \\
\text { (cardiovascular disease, osteoporosis, } \\
\text { diabetes, hypertension, obesity). }\end{array}$ \\
\hline$>$ & Postpartum weight retention. & $\begin{array}{l}\text { Adverse outcomes (musculoskeletal } \\
\text { injury, trauma, dehydration, } \\
\text { hyperthermia, cardiovascular } \\
\text { or respiratory events, maternal } \\
\text { hypoglycaemia, fatigue). }\end{array}$ \\
\hline 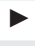 & Glucose tolerance. & - Gestational age at birth. \\
\hline$>$ & $\begin{array}{l}\text { Preterm/prelabour rupture of } \\
\text { membranes. }\end{array}$ & D Birth weight. \\
\hline 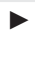 & Diastasis recti. & $\begin{array}{l}\text { Body composition (newborn } \\
\text { adiposity, body mass index). }\end{array}$ \\
\hline$>$ & $\begin{array}{l}\text { Fetal responses to physical activity } \\
\text { (fetal heart rate, uterine/umbilical } \\
\text { blood flow). }\end{array}$ & $\begin{array}{l}\text { Birth complications (including } \\
\text { shoulder dystocia, brachial plexus } \\
\text { injury, APGAR, neonatal intensive } \\
\text { care unit admittance, metabolic } \\
\text { acidosis). }\end{array}$ \\
\hline 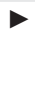 & $\begin{array}{l}\text { Low birth weight (small for } \\
\text { gestational age }<2500 \mathrm{~g},<10 \text { th/15th } \\
\text { percentile for gestational age). }\end{array}$ & - Hyperbilirubinaemia. \\
\hline$>$ & Intrauterine growth restriction. & $\begin{array}{l}\text { Offspring developmental milestones } \\
\text { (cognitive, psychosocial, motor skills). }\end{array}$ \\
\hline 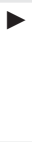 & $\begin{array}{l}\text { High birth weight (large for } \\
\text { gestational age, macrosomia, }>4000 \\
\text { g, >90th percentile for gestational } \\
\text { age). }\end{array}$ & \\
\hline$>$ & Neonatal hypoglycaemia. & \\
\hline$>$ & $\begin{array}{l}\text { Long-term offspring outcomes } \\
\text { (obesity, cardiovascular and } \\
\text { metabolic diseases). }\end{array}$ & \\
\hline
\end{tabular}

Academy of Sport and Exercise Medicine, Exercise is Medicine Canada, and a public health representative (the Middlesex-London Health Unit). Prior to convening the Guidelines Consensus Panel, 10 pregnant women were recruited by convenience sampling and invited to provide input on the perceived benefits and harms of physical activity, as well as to identify pregnancy outcomes that were most important to them. During consensus meeting 1, the Guidelines Consensus Panel selected 37 outcomes related to maternal, fetal and neonatal health, 20 of which were rated as 'critical' and 17 as 'important', taking into consideration the feedback from pregnant women and the perspective of obstetric care providers based on their expert opinion (see table 1 for outcomes). The Guidelines Consensus Panel also identified four a priori subgroups of women believed to be at higher risk of pregnancy 


\begin{tabular}{|c|c|}
\hline Absolute contraindications & Relative contraindications \\
\hline $\begin{array}{l}\text { Ruptured membranes, premature } \\
\text { labour. }\end{array}$ & Recurrent pregnancy loss. \\
\hline $\begin{array}{l}\text { Unexplained persistent vaginal } \\
\text { bleeding. }\end{array}$ & - History of spontaneous preterm birth. \\
\hline $\begin{array}{l}\text { Placenta praevia after } 28 \text { weeks' } \\
\text { gestation. }\end{array}$ & - Gestational hypertension. \\
\hline - Pre-eclampsia. & - Symptomatic anaemia. \\
\hline - Incompetent cervix. & - Malnutrition. \\
\hline - Intrauterine growth restriction. & - Eating disorder. \\
\hline $\begin{array}{l}\text { High-order multiple pregnancy (eg, } \\
\text { triplets) }\end{array}$ & Twin pregnancy after the 28th week. \\
\hline $\begin{array}{l}\text { Uncontrolled type I diabetes, } \\
\text { uncontrolled hypertension or } \\
\text { uncontrolled thyroid disease. }\end{array}$ & $\begin{array}{l}\text { Mild/moderate cardiovascular or } \\
\text { respiratory disease. }\end{array}$ \\
\hline $\begin{array}{l}\text { Other serious cardiovascular, } \\
\text { respiratory or systemic disorder. }\end{array}$ & Other significant medical conditions. \\
\hline
\end{tabular}

complications. These include women who were previously inactive, women diagnosed with gestational diabetes mellitus, women categorised as overweight or obese prior to pregnancy, and women $>35$ years of age. Twelve systematic reviews were prepared to describe the effect of physical activity on 'critical' and 'important' outcomes, and to present the balance between benefits and potential harms of physical activity. ${ }^{2-13}$ A comprehensive search was created and run by a research librarian on MEDLINE, EMBASE, PsycINFO, Cochrane Database of Systematic Reviews, Cochrane Central Register of Controlled Trials, Scopus and Web of Science Core Collection, CINAHL Plus with Full Text, Child Development \& Adolescent Studies, Education Resources Information Center, SPORTDiscus, ClinicalTrials.gov and the Trip Database up to 6 January 2017 for randomised and observational studies examining the relationships between prenatal physical activity and the identified health outcomes in women without contraindication. Overall, 27624 titles and abstracts were screened, and 675 unique studies were included. The recommendations were primarily based on a subset of exercise-only randomised controlled trials (RCT; $n=104)$ and cohort studies $(n=4)$. Detailed methodology and the results are available in two issues of the British Journal of Sports Medicine and the Journal of Obstetrics and Gynaecology Canada. ${ }^{2-1322}$ Consensus meeting 2 was held in October 2017 to review evidence and draft the recommendations. In April 2018, feedback from stakeholder groups and pregnant women was solicited through the networks of the Guidelines Consensus Panel via surveys in both English and French. The recommendations were revised based on this feedback, and a second round of surveys were distributed. A draft of the Guidelines was shared with the boards of CSEP, SOGC, as well as the Guidelines Consensus Panel members in May 2018. The Guidelines were further revised, and the final version of the recommendations was sent to the SOGC and CSEP Executive for review and endorsement.

\section{WHO SHOULD BE PHYSICALLY ACTIVE DURING PREGNANCY?}

These Guidelines are intended for women who do not have contraindications (see table 2) that would prevent them from engaging in physical activity. Women with absolute contraindications may continue the usual activities of daily living but should not participate in more strenuous exercise. Women with relative contraindications should discuss the advantages and disadvantages of moderate-to-vigorous intensity physical activity with their obstetric care provider.

\section{Recommendation 1}

All women without contraindication should be physically active throughout pregnancy. Strong recommendation, moderate-quality evidence.

Specific subgroups were examined:

- Women who were previously inactive. Strong recommendation, moderate-quality evidence.

- Women diagnosed with gestational diabetes mellitus. Weak recommendation, low-quality evidence.

- Women categorised as overweight or obese (prepregnancy body mass index $\geq 25 \mathrm{~kg} / \mathrm{m}^{2}$ ). Strong recommendation, low-quality evidence.

One hundred and four exercise-only RCTs were identified regarding the effects of physical activity on one or more prioritised outcomes. These data represent 'moderate' quality evidence of a beneficial effect of prenatal physical activity on maternal, fetal and newborn health outcomes. Prenatal physical activity was associated with a reduction in the odds of gestational diabetes mellitus (38\%; 39 fewer per thousand (from 25 fewer to 50 fewer)), pre-eclampsia (41\%; 12 fewer per thousand (from 2 fewer to 19 fewer)), gestational hypertension (39\%; 15 fewer per thousand (from 6 fewer to 22 fewer)), prenatal depression $(67 \% ; 134$ fewer per thousand (from 90 fewer to 163 fewer)) and macrosomia (39\%; 30 fewer per thousand (from 6 fewer to 47 fewer)) without increasing the odds of adverse outcomes including preterm birth, low birth weight, miscarriage and perinatal mortality. ${ }^{2-5} 7$ Feedback from stakeholder $(n=429)$ and pregnant women $(n=170)$ indicated that a large proportion of women agreed that the benefits of physical activity during pregnancy outweighed the costs (51\% strongly agree, $22 \%$ agree $)$, and that physical activity was feasible $(27 \%$ strongly agree, 41\% agree), acceptable (36\% strongly agree, $45 \%$ agree) and equitable (62\% strongly agree, $21 \%$ agree) for pregnant women. The survey results supported strong recommendations in favour of prenatal physical activity.

Physical activity during the first trimester did not increase the odds of miscarriage or congenital anomalies. ${ }^{3} 8$ Importantly, there was also evidence suggesting that not engaging in physical activity from the first trimester increased the odds of pregnancy complications (ie, gestational diabetes mellitus, pre-eclampsia, gestational hypertension, excessive gestational weight gain and severity of depressive symptoms). ${ }^{2}{ }^{21123-25}$ As such, it is the opinion of the Guidelines Consensus Panel that physical activity should be encouraged throughout pregnancy.

Regarding a priori subgroup analyses, the evidence supported recommendations in favour of physical activity during pregnancy across subgroups, and the survey results indicated a large proportion of women and stakeholders agreed that the benefits of physical activity outweighed the costs, and that physical activity was feasible, acceptable and equitable. The Guidelines Consensus Panel made a strong recommendation for previously inactive women based on moderate-quality data and the results of the surveys. This was a strong recommendation because, despite low-quality evidence supporting physical activity during pregnancy for women categorised as overweight or obese, there was evidence from RCTs demonstrating an improvement in gestational weight gain and blood glucose. The recommendation for women with gestational diabetes mellitus was a weak 
recommendation because the quality of evidence was low, and the net benefit between women who were physically active and those who did not was small. No studies exclusively examining women 35 years of age or older were identified; therefore, no recommendation for this subgroup was provided.

\section{WHAT PHYSICAL ACTIVITY IS RECOMMENDED DURING PREGNANCY? Recommendation 2}

Pregnant women should accumulate at least 150 min of moderate-intensity physical activity each week to achieve clinically meaningful reductions in pregnancy complications. Strong recommendation, moderate-quality evidence.

\section{Recommendation 3}

Physical activity should be accumulated over a minimum of 3 days per week; however, being active every day is encouraged. Strong recommendation, moderate-quality evidence.

\section{Recommendation 4}

Pregnant women should incorporate a variety of aerobic exercise and resistance training activities to achieve greater benefits. Adding yoga and/or gentle stretching may also be beneficial. Strong recommendation, high-quality evidence.

\section{Recommendation 5}

PFMT (eg, Kegel exercises) may be performed on a daily basis to reduce the odds of urinary incontinence. Instruction on the proper technique is recommended to obtain optimal benefits. Weak recommendation, low-quality evidence.

\section{Recommendation 6}

Pregnant women who experience light-headedness, nausea or feel unwell when they exercise flat on their back should modify their exercise position to avoid the supine position. Weak recommendation, very low-quality evidence.

The results of the systematic reviews identified that, compared with no physical activity, accumulating at least $150 \mathrm{~min}$ of moderate-intensity physical activity over three or more days per week was associated with clinically meaningful reductions in the odds of developing gestational diabetes mellitus, pre-eclampsia and gestational hypertension. ${ }^{5}$ Accumulating more physical activity (frequency, duration or volume) over the week was associated with greater benefits; however, physical activity below the recommendations also incurred some benefits. The findings of the systematic reviews also demonstrated that combining aerobic exercise and resistance training during pregnancy was more effective at improving health outcomes than interventions focused on aerobic exercise alone. ${ }^{713}$ We further identified a dose-response relationship between increasing intensities of physical activity and decreasing odds of pre-eclampsia, gestational diabetes, gestational hypertension, and a reduction in depressive symptoms and circulating maternal blood glucose. ${ }^{256}$ It is important to note that for many outcomes, lower intensity physical activity also imparts benefits. Therefore, pregnant women should be encouraged to be physically active, even if they are unable to meet these recommendations. However, evidence was not identified regarding the safety or additional benefit of exercising at levels significantly above the recommendations. Indeed, the highest intensity of physical activity prescribed in the RCTs was 7.0 metabolic equivalents (METs; equivalent to jogging). As such the safety and efficacy of chronic high-intensity

\begin{tabular}{lll}
\hline Table 3 & Heart rate ranges for pregnant women \\
\hline Maternal age & Intensity & Heart rate range (beats/min) \\
\hline$<29$ & Light & $102-124$ \\
& Moderate & $125-146$ \\
& Vigorous & $147-169^{*}$ \\
$30+$ & Light & $101-120$ \\
& Moderate & $121-141$ \\
& Vigorous & $142-162^{*}$
\end{tabular}

Moderate-intensity physical activity (40\%-59\% heart rate reserve (HRR)); vigorousintensity physical activity $(60 \%-80 \% \mathrm{HRR})$.

Target heart rate ranges were derived from peak exercise tests in medically screened, low-risk pregnant women. ${ }^{26} 27$

*As there is minimal information regarding the impact of physical activity at the upper end of the vigorous-intensity heart rate ranges, women wishing to be active at this intensity (or beyond) are encouraged to consult their obstetric care provider.

physical activity for the mother, the fetus and the neonate are not known. Accordingly, the Guidelines Consensus Panel recommends high-intensity physical activity only in a monitored environment. Moderate-intensity physical activity is recommended throughout pregnancy.

Maternal heart rate is a measure of physical activity intensity. Table 3 presents pregnancy-specific target heart rate zones for women who wish to monitor their heart rate during physical activity. ${ }^{2627}$ Other measures of physical activity intensity include the 'talk test'. As the term 'talk test' implies, the woman is at a comfortable intensity if she is able to maintain a conversation during physical activity and should reduce the intensity if this is not possible.

The Guidelines Consensus Panel developed recommendations on two specific types of physical activity: PFMT and supine exercise. PFMT is recommended to prevent urinary incontinence even though it was not rated as a 'critical' outcome and was based on low-quality evidence. Prenatal PFMT is associated with a 50\% reduction in prenatal and 35\% reduction in postnatal urinary incontinence, which the Guidelines Consensus Panel deemed warranted a weak recommendation. ${ }^{9}$ The Guidelines Consensus Panel recommended instruction on proper technique to obtain optimal benefits. The recommendation for women to modify their physical activity position to avoid the supine position when feeling unwell was deemed weak as the quality of evidence was very low. ${ }^{12}$ In addition, although harms were investigated, there was limited information from RCTs to inform the balance of benefits and harms. This recommendation was primarily based on expert opinion, resulting in a weak recommendation.

\section{CONSIDERATIONS FOR IMPLEMENTATION}

The following guidance is based on the expert opinion of the Guidelines Consensus Panel.

\section{Safety precautions}

General safety precautions for women who are pregnant and physically active are presented in box 1 . Some sport activities carry significant risk in pregnancy and are considered contraindicated. Women should not scuba-dive in pregnancy, as the fetus is not protected from decompression sickness and gas embolism. ${ }^{28}$ Women are recommended to avoid activities which involve physical contact or danger of falling, which may increase the risk of fetal trauma. These activities include, but are not limited to, horseback riding, downhill skiing, ice hockey, gymnastics or Olympic lifts. Pregnant women are recommended to avoid non-stationary cycling as this activity may carry a higher 
Box 1 Safety precautions for prenatal physical activity

- Avoid physical activity in excessive heat, especially with high humidity.

- Avoid activities which involve physical contact or danger of falling.

- Avoid scuba diving.

- Lowlander women (ie, living below $2500 \mathrm{~m}$ ) should avoid physical activity at high altitude ( $>2500 \mathrm{~m})$. Those considering physical activity above those altitudes should seek supervision from an obstetric care provider with knowledge of the impact of high altitude on maternal and fetal outcomes.

- Those considering athletic competition or exercising significantly above the recommended guidelines should seek supervision from an obstetric care provider with knowledge of the impact of high-intensity physical activity on maternal and fetal outcomes.

- Maintain adequate nutrition and hydration-drink water before, during and after physical activity.

- Know the reasons to stop physical activity and consult a qualified healthcare provider immediately if they occur (see Box 2).

risk of falling due to changes in body mechanics and the ability to respond to the environment (eg, traffic, unsteady surfaces) as pregnancy progresses. As an alternative, brisk walking, stationary cycling, swimming or aquafit are aerobic activities that are associated with less risk of falling or physical contact. With appropriate acclimatisation, moderate-intensity physical activity at altitudes up to $1800-2500 \mathrm{~m}(6000-8250 \mathrm{ft})$ does not appear to significantly alter maternal or fetal well-being. ${ }^{29} 30$ However, women should be wary of hiking in a location where they might fall. It is also important that women stay hydrated and avoid vigorous physical activity in excessive heat, especially with high humidity, to avoid dehydration (eg, hot yoga).

During pregnancy, some women will experience a visible separation of their abdominal muscles, called diastasis recti. Those women are counselled to seek physiotherapy advice and avoid abdominal strengthening exercises (eg, abdominal curls) as this may worsen the condition, ${ }^{31}$ increasing the likelihood of requiring postnatal repair. However, continuing aerobic exercise such as walking is associated with decreased odds of developing diastasis recti. ${ }^{4}$ While there has been less research on resistance exercises as compared with aerobic exercises in pregnancy, available evidence regarding resistance exercise in pregnancy has not identified adverse impacts on the mother, the fetus or the neonate. Therefore, resistance training that adheres to the safety considerations in box 1 is encouraged. Further, our systematic reviews identified that 'mixed' interventions combining aerobic and resistance training activities demonstrated greater improvements in pregnancy outcomes than aerobic activity alone. Women who experience light-headedness with excessive Valsalva manoeuvre (straining while holding one's breath) when exercising should avoid the breath-hold.

Women considering athletic competition or exercising significantly above the recommended guidelines should speak to their obstetric care provider to clarify risk and make modifications, if necessary. Elite athletes who continue to train during pregnancy are advised to seek supervision from an obstetric care provider with knowledge of the impact of vigorous-intensity physical activity on maternal, fetal and neonatal outcomes. Recently, the
Box 2 Reasons to stop physical activity and consult a healthcare provider

- Persistent excessive shortness of breath that does not resolve on rest.

- Severe chest pain.

- Regular and painful uterine contractions.

- Vaginal bleeding.

- Persistent loss of fluid from the vagina indicating rupture of the membranes.

- Persistent dizziness or faintness that does not resolve on rest.

IOC released a series of recommendations to guide elite athletes during and following pregnancy. ${ }^{32-35}$

Finally, it is suggested that a warm-up and cool-down period be included in any physical activity regimen. Ligaments become relaxed during pregnancy due to increasing hormone levels and may impact on the range of movement, thereby increasing the risk of injury. ${ }^{36}$

All women should stop activity and seek medical attention if they experience any of the symptoms identified in box 2 .

\section{HOW TO START BEING ACTIVE DURING PREGNANCY?}

Previously inactive women are encouraged to start physical activity in pregnancy but may need to begin gradually, at lower intensity and increase the duration and intensity as their pregnancy progresses. It is important to note that when doseresponse relationships between physical activity and pregnancy outcomes were identified, more physical activity (frequency, intensity, duration and volume) was associated with greater health benefits. However, an upper limit was not established.

It may be difficult for some women to follow these Guidelines without additional support or advice. Obstetric care professionals and exercise professionals must carefully consider the potential costs and perceived barriers to prenatal physical activity to facilitate participation. These Guidelines may be appropriate for women with a disability or medical condition; however, an obstetric care professional should be consulted for additional guidance. Although the majority of the evidence base for these recommendations used supervised exercise, physical activity during pregnancy does not need to be done in a supervised setting or with any specific equipment. For those with financial or other barriers to participating in organised exercise, activities as simple as walking can have positive benefits.

\section{Other healthy lifestyle habits during pregnancy}

In addition to physical activity, other components of a healthy lifestyle including adequate nutrition and sleep, as well as abstinence from smoking, alcohol, marijuana and illicit drugs, are highly encouraged. . $^{3-39}$

\section{RESOURCES FOR THE HEALTHCARE PROVIDER, EXERCISE PROFESSIONAL AND PREGNANT WOMEN}

The Physical Activity Readiness Medical Examination for Pregnancy (PARmed-X for Pregnancy) was developed by the CSEP and endorsed by the SOGC and Health Canada (and available through CSEP's website at www.csep.ca/forms.asp) as an aid for medical professionals to identify contraindications for pregnant women prior to their participation in physical activity. ${ }^{40}$ 


\section{SUMMARY}

The 2019 Canadian Guideline for Physical Activity throughout Pregnancy represent a foundational shift in our view of prenatal physical activity from a recommended behaviour to improve quality of life, to a specific prescription for physical activity to reduce pregnancy complications and optimise health across the lifespan of two generations. It is critical that these Guidelines be implemented into clinical practice to achieve the significant and potentially lifelong health benefits for both the mother and the child.

\section{Author affiliations}

${ }^{1} \mathrm{R}$ Samuel McLaughlin Foundation-Exercise and Pregnancy Laboratory, School of Kinesiology, Faculty of Health Sciences, Department of Anatomy and Cell Biology, Schulich School of Medicine \& Dentistry, Children's Health Research Institute, The University of Western Ontario, London, Ontario, Canada

${ }^{2}$ Program for Pregnancy and Postpartum Health, Faculty of Kinesiology, Sport and Recreation, Women and Children's Health Research Institute, Alberta Diabetes Institute, University of Alberta, Edmonton, Alberta, Canada

${ }^{3}$ Department of Human Kinetics, Universite du Quebec a Trois-Rivieres, Trois-Rivieres, Quebec, Canada

${ }^{4}$ Department of Obstetrics and Gynecology, Queen's University, Kingston, Ontario, Canada

${ }^{5}$ Independent Researcher, Ottawa, Ontario, Canada

${ }^{6}$ Healthy Active Living and Obesity Research Group, Children's Hospital of Eastern Ontario Research Institute, Ottawa, Ontario, Canada

${ }^{7}$ Clinical Research Unit, Children's Hospital of Eastern Ontario Research Institute, Ottawa, Ontario, Canada

${ }^{8}$ School of Human Kinetics, Faculty of Health Sciences, University of Ottawa, Ottawa, Ontario, Canada

${ }^{9}$ Canadian Society for Exercise Physiology, Ottawa, Ontario, Canada

${ }^{10}$ Facultad de Ciencias de la Actividad Física y del Deporte-INEF, Universidad

Politécnica de Madrid, Madrid, Spain

${ }^{11}$ College of Kinesiology, University of Saskatchewan, Saskatoon, Canada

${ }^{12}$ Department of Family and Community Medicine, Sunnybrook Health Sciences Centre, Toronto, Ontario, Canada

${ }^{13}$ Department of Family and Community Medicine, University of Toronto, Granovsky Gluskin Family Medicine Centre, Sinai Health System, Sinai Health System, Toronto, Ontario, Canada

${ }^{14}$ Canadian Association of Midwives, Toronto, Canada

${ }^{15}$ John W Scott Health Sciences Library, University of Alberta, Edmonton, Alberta, Canada

${ }^{16}$ Middlesex-London Health Unit, London, Ontario, Canada

${ }^{17}$ School of Health and Human Services, Camosun College, Victoria, Canada

Collaborators SOGC Maternal Fetal Medicine Committee: Hayley Bos, MD, Victoria, BC (co-chair); Richard Brown, Beaconsfield, QC; Emmanuel Bujold, MD, Quebec, QC; Sheryl Choo, MD, London, ON; Venu Jain, MD, Edmonton, AB; Lisa Kuechler, RN, Victoria, BC; Heather Martin, RM, Edmonton, AB; N Lynne McLeod, MD, Halifax, NS; Savas Menticoglou, MD, Winnipeg, MB; William Mundle, MD, Windsor, ON (co-chair); Kirsten Niles, MD, Toronto, ON; Frank Sanderson, MD, Saint John, NB; Jennifer Walsh, MD, Calgary, AB. CSEP Board of Directors: Nota Klentrou, PhD, St Catharines, ON (Chair); Adam Upshaw, PhD, St Catharines, ON; Thomas Hawke, PhD, Hamilton, ON; Kristin Lane, PhD, Victoria, BC; Jennifer Jakobi, PhD Kelowna, BC Christopher Perry, PhD, Toronto, ON; Michael Plyley, PhD, St Catherines, ON; Kevin Power, PhD, St John's NFLD; Ginger Lamoureux, BA, BSc, Shilo, MB; Shilpa Dogra, PhD, Oshawa, ON; Kevin Boldt, MSc, Calgary, AB.

Contributors The Guidelines Steering Committee (MHD (Chair), MFM, S-MR, GAD, VJP, CEG, AJG, NB, KBA, MD, RB, PC, KF, MF, JK, TN, LS, DS, LZ) developed the recommendations. MHD drafted the guidelines, and the Guidelines Steering Committee (MFM, SMR, GAD, VJP, CEG, AJG, NB) revised the document. All authors provided feedback on the manuscript and approved the final version.

Funding Knowledge Synthesis Grant from the Canadian Institutes of Health Research. MHD is funded by an Advancing Women's Heart Health Initiative New Investigator Award supported by Health Canada and the Heart and Stroke Foundation of Canada.

Disclaimer Disclosure statements have been received from all authors. This document reflects emerging clinical and scientific advances on the date issued and is subject to change. The information should not be construed as dictating an exclusive course of treatment or procedure to be followed. Local institutions can dictate amendments to these opinions. They should be well documented if modified at the local level. None of these contents may be reproduced in any form without prior written permission of the publisher. Patients have the right and responsibility to make informed decisions about their care in partnership with their healthcare providers. In order to facilitate informed choice, patients should be provided with information and support that is evidence-based, culturally appropriate and tailored to their needs. The values, beliefs and individual needs of each patient and their family should be sought, and the final decision about the care and treatment options chosen by the patient should be respected.

Competing interests None declared.

Patient consent Not required.

Provenance and peer review Not commissioned; internally peer reviewed.

Author note The following organisations have reviewed this document and endorse the Joint SOGC/CSEP 2019 Canadian Guideline for Physical Activity throughout Pregnancy: Alberta Health Services-Healthy Families and Children, Canadian Academy of Sport Medicine, Canadian Association of Midwives, Directorate for Chief Medical Officer and Chief Scientist Office of Scotland, Exercise is Medicine Canada, Ontario Public Health Association, ParticipACTION, Perinatal Services BC, and Sociedad Espanola de Ginecologia y Obstetricia (the Spanish Society of Gynecology and Obstetrics).

\section{REFERENCES}

1 American College of Sports Medicine. ACSM's Guidelines for Exercise Testing and Prescription. 9th ed. Philadelphia: Wolters Kluwer/Lippincott, Williams \& Wilkins, 2013.

2 Davenport MH, McCurdy AP, Mottola MF, et al. Impact of prenatal exercise on both prenatal and postnatal anxiety and depressive symptoms: a systematic review and meta-analysis. Br J Sports Med 2018;52:1376-85.

3 Davenport MH, Kathol AJ, Mottola MF, et al. Prenatal exercise is not associated with fetal mortality: a systematic review and meta-analysis. Br J Sports Med 2018. [Epub ahead of print].

4 Davenport MH, Ruchat S-M, Sobierajski F, et al. Impact of prenatal exercise on maternal harms, labour and delivery outcomes: a systematic review and metaanalysis. Br J Sports Med 2018. [Epub ahead of print].

5 Davenport MH, Ruchat S-M, Poitras VJ, et al. Prenatal exercise for the prevention of gestational diabetes mellitus and hypertensive disorders of pregnancy: a systematic review and meta-analysis. Br J Sports Med 2018;52:1367-75.

6 Davenport MH, Sobierajski F, Mottola MF, et al. Glucose response to acute and chronic exercise during pregnancy: a systematic review and meta-analysis. Br I Sports Med 2018:52:1357-66.

7 Davenport MH, Meah VL, Ruchat S-M, et al. The impact of prenatal maternal exercise on neonatal and childhood outcomes: a systematic review and meta-analysis. $\mathrm{Br} J$ Sports Med 2018:52:1386-96.

8 Davenport MH, Yoo C, Mottola MF, et al. Effects of prenatal exercise on incidence of congenital anomalies and hyperthermia: a systematic review and meta-analysis. $\mathrm{Br} J$ Sports Med 2018. [Epub ahead of print].

9 Davenport MH, Nagpal T, Mottola MF, et al. Prenatal exercise (including but not limited to pelvic floor muscle training) and urinary incontinence during and following pregnancy: A systematic review and meta-analysis. Br J Sports Med 2018;52:1397-404.

10 Davenport MH, Marchand AA, Mottola MF, et al. Exercise for the prevention and treatment of low back, pelvic girdle and lumbopelvic pain during pregnancy: a systematic review and meta-analysis. Br J Sports Med 2018. [Epub ahead of print].

11 Ruchat S-M, Mottola MF, Skow RJ, et al. Effectiveness of exercise interventions in the prevention of excessive gestational weight gain and postpartum weight retention: A systematic review and meta-analysis. Br J Sports Med 2018;52:1347-56

12 Mottola MF, Nagpal TS, Begeginski R, et al. Is supine exercise associated with adverse maternal and fetal outcomes? A systematic review. Br J Sports Med 2018 [Epub ahead of print].

13 Skow RJ, Davenport MH, Mottola MF, et al. Effects of prenatal exercise on fetal heart rate, umbilical and uterine blood flow: a systematic review and meta-analysis. $\mathrm{Br} \mathrm{J}$ Sports Med 2018 [Epub ahead of print]

14 Evenson KR, Barakat R, Brown WJ, et al. Guidelines for Physical Activity during Pregnancy: Comparisons From Around the World. Am J Lifestyle Med 2014;8:102-21.

15 Evenson KR, Wen F. Prevalence and correlates of objectively measured physical activity and sedentary behavior among US pregnant women. Prev Med 2011;53(1-2):39-43.

16 Coll CV, Domingues MR, Gonçalves $H$, et al. Perceived barriers to leisure-time physical activity during pregnancy: $\mathrm{A}$ literature review of quantitative and qualitative evidence. J Sci Med Sport 2017;20:17-25.

17 Lavery JA, Friedman AM, Keyes KM, et al. Gestational diabetes in the United States: temporal changes in prevalence rates between 1979 and 2010. BJOG 2017:124:804-13.

18 Wallis $A B$, Saftlas AF, Hsia J, et al. Secular trends in the rates of preeclampsia, eclampsia, and gestational hypertension, United States, 1987-2004. Am J Hypertens 2008;21:521-6. 
19 Ferraro ZM, Gaudet L, Adamo KB. The potential impact of physical activity during pregnancy on maternal and neonatal outcomes. Obstet Gynecol Surv 2012;67:99-110.

20 Reyes LM, Davenport MH. Exercise as a therapeutic intervention to optimize fetal weight. Pharmacol Res 2018;132:160-7.

21 Brouwers MC, Kho ME, Browman GP, et al. AGREE II: advancing guideline development, reporting, and evaluation in health care. Prev Med 2010;51:421-4.

22 Davenport MH, Ruchat S-M, Mottola MF, et al. 2019 Canadian guideline for physical activity throughout pregnancy: methodology. Journal of Obstetrics and Gynaecology Canada 2018;40(11)

23 Aune D, Saugstad OD, Henriksen T, et al. Physical activity and the risk of preeclampsia: a systematic review and meta-analysis. Epidemiology 2014;25:331-43.

24 Aune D, Sen A, Henriksen T, et al. Physical activity and the risk of gestational diabetes mellitus: a systematic review and dose-response meta-analysis of epidemiological studies. Eur J Epidemiol 2016;31:967-97.

25 Davenport MH, Ruchat SM, Giroux I, et al. Timing of excessive pregnancy-related weight gain and offspring adiposity at birth. Obstet Gynecol 2013;122(2 Pt 1):255-61.

26 Davenport MH, Charlesworth S, Vanderspank D, et al. Development and validation of exercise target heart rate zones for overweight and obese pregnant women. Appl Physiol Nutr Metab 2008;33:984-9.

27 Mottola MF, Davenport MH, Brun CR, et al.V02peak prediction and exercise prescription for pregnant women. Med Sci Sports Exerc 2006;38:1389-95.

28 Camporesi EM. Diving and pregnancy. Semin Perinatol 1996;20:292-302.

29 Artal R, Fortunato V, Welton A, et al. A comparison of cardiopulmonary adaptations to exercise in pregnancy at sea level and altitude. Am J Obstet Gynecol 1995;172(4 Pt 1): $1170-80$

30 Jean D, Moore LG. Travel to high altitude during pregnancy: frequently asked questions and recommendations for clinicians. High Alt Med Biol 2012;13:73-81
31 Mota P, Pascoal AG, Carita Al, et al. The Immediate Effects on Inter-rectus Distance of Abdominal Crunch and Drawing-in Exercises During Pregnancy and the Postpartum Period. J Orthop Sports Phys Ther 2015;45:781-8.

32 Bo K, Artal R, Barakat R, et al. Exercise and pregnancy in recreational and elite athletes: 2016/17 evidence summary from the IOC expert group meeting, Lausanne. Part 4-Recommendations for future research. Br J Sports Med 2017;51:1724-6.

33 Bo K, Artal R, Barakat R, et al. Exercise and pregnancy in recreational and elite athletes: 2016/17 evidence summary from the IOC Expert Group Meeting, Lausanne. Part 3-exercise in the postpartum period. Br J Sports Med 2017:51:1516-25.

34 Bo K, Artal R, Barakat R, et al. Exercise and pregnancy in recreational and elite athletes: 2016 evidence summary from the IOC expert group meeting, Lausanne. Part 2-the effect of exercise on the fetus, labour and birth. Br J Sports Med 2016:50:1297-305

35 Bo K, Artal R, Barakat R, et al. Exercise and pregnancy in recreational and elite athletes: 2016 evidence summary from the IOC expert group meeting, Lausanne. Part 1 -exercise in women planning pregnancy and those who are pregnant. $\mathrm{Br} J$ Sports Med 2016:50:571-89.

36 Wolfe LA. Pregnant women and endurance exercise. In: Shephard RJ, Astrand PO, eds. Endurance in sport. 2nd ed. London: Blackwell Science, 2000:531-46.

37 Ferraro ZM, Chaput JP, Gruslin A, et al. The potential value of sleep hygiene for a healthy pregnancy: a brief review. ISRN Family Med 2014;2014:1-7.

38 O'Connor DL, Blake J, Bell R, et al. Canadian Consensus on Female Nutrition: Adolescence, Reproduction, Menopause, and Beyond. J Obstet Gynaecol Can 2016:38:508-54

39 Wong S, Ordean A, Kahan M. Society of Obstetricians and Gynecologists of Canada. SOGC clinical practice guidelines: Substance use in pregnancy: no. 256, April 2011. Int J Gynaecol Obstet 2011;114:190-202.

40 PARmed-X for Pregnancy (2013): Canadian Society for Exercise Physiology, 2013. 